\title{
10. THE BOREHOLE SEISMIC EXPERIMENT IN HOLE 395A: ENGINEERING AND INSTALLATION ${ }^{1}$
}

\author{
J. A. Ballard, Naval Ocean Research and Development Activity, NSTL Station \\ Carl C. Mulcahy, Teledyne Geotech \\ and \\ R. L. Wallerstedt and E. L. Kiser, Global Marine Development, Inc. ${ }^{2}$
}

\begin{abstract}
The primary engineering goal of the Marine Seismic System (MSS) experiment on Leg 78B was to test the feasibility of installing large instruments in a borehole by means of a package carried external to the drill string. In addition to seismometers, the instrument package contained triaxial accelerometers to measure impacts associated with reentry and thermistors to measure heat generated by electronic components. Maximum vertical accelerations of about $6 g$ occurred when the seismometer package entered the reentry cone; maximum horizontal accelerations of $5 \mathrm{~g}$ were recorded when the seismometer package was hydraulically shifted into the lowering position. Lesser accelerations were noted when the instrument was handled aboard ship and when it touched down at the bottom of the borehole. Cable control adequate to prevent cable-drill string entanglement was achieved with a dynamic tension of load plus about $350 \mathrm{lb}$. These stresses are considered to be within reasonable design tolerances for most borehole instruments.
\end{abstract}

\section{INTRODUCTION}

For the past several years, the Advanced Research Projects Agency (ARPA; Table 1) has sponsored the development of a broadband, triaxial seismometer station, the Marine Seismic System (MSS), which is similar in capabilities to land-based Seismic Research Observatories (SRO) but is designed to monitor seismic events from a borehole in the seafloor. The Naval Ocean Research and Development Activity (NORDA), a field activity of the Chief of Naval Research, directed the development, installation, and operation of the tool; Global Marine Development, Inc. was the deployment engineering contractor; the downhole instruments were designed and built by Teledyne Geotech, Inc.

Leg 78B provided a unique opportunity to test a prototype of the seismometer system and to evaluate installation techniques, because the purpose of the leg was to reoccupy a deep basement hole (395A) drilled on an earlier leg (45) in order to conduct geophysical experiments. Although the wideband, wide dynamic range seismic data obtained on the leg were used for several scientific studies (see Adair, et al., and Jacobson, et al., this volume), the primary purpose of this chapter is to evaluate the engineering techniques and equipment used. An unusual feature of the Borehole Instrument Package, or BIP, was its size-over $26 \mathrm{ft}$. long and $8 \mathrm{in}$. in diameter. Because the tool could not fit through the drill string, it had to be lowered to the seafloor by means of an external carriage (Fig. 1). In addition to gaining field experience with this system for future installation, we had spe-

\footnotetext{
${ }^{1}$ Hyndman, R. D., Salisbury, M. H., et al., Init. Repts. DSDP, 78B: Washington (U.S. Govt, Printing Service).

2 Addresses: (Ballard) Naval Ocean Research and Development Activity, NSTL Station, MS 39529; (Mulcahy) Teledyne Geotech, P.O. Box 401676, Garland, TX 750-410-676; (Wallerstedt and Kiser) Global Marine Development, Inc., Newport Beach, CA 92663.
}

Table 1. Acronyms.

\begin{tabular}{ll}
\hline ARPA & Advanced Research Projects Agency \\
BIP & Borehole Instrument Package \\
CRT & Cathode ray tube \\
D/A & Digital to analog \\
EM & Electromechanical \\
HC & Heave compensator \\
IRIG B & Inter-Range Instrumentation Group Format B \\
MSS & Marine Seismic System \\
NORDA & Naval Ocean Research and Development Activity \\
OBS & Ocean bottom seismometer \\
PCM & Pulse code modulated \\
SOH & State of health \\
SRO & Seismic Research Observatory \\
STC & Shipboard test console \\
UPS & Uninterruptable Power System \\
\hline
\end{tabular}

cific engineering goals to be addressed that dictated the direction and scope of the experiment at Site 395:

1. Could the MSS borehole instrument survive the shocks inherent in drill ship installation? The borehole instrument was equipped with triaxial accelerometers to measure impacts generated by reentry procedures. The broadband seismometers, as configured, were designed to survive installation impacts of about $20 \mathrm{~g}$. Thus knowledge of reentry impacts was essential for defining both the techniques needed for safe installation of the more fragile seismometers planned for later deployments and for protecting the instrument against such impacts. Landbased impact tests indicated that the instrument and reentry assembly were sufficiently shock mounted to survive reentry, but the applicability of these data to actual conditions had to be determined.

2. Would surface and bottom currents cause cabledrill pipe entanglement? To assess the effects of current shear on drill-string motion and cable entanglement, the Lynch (T-AGOR[Auxiliary General Oceanographic Re- 

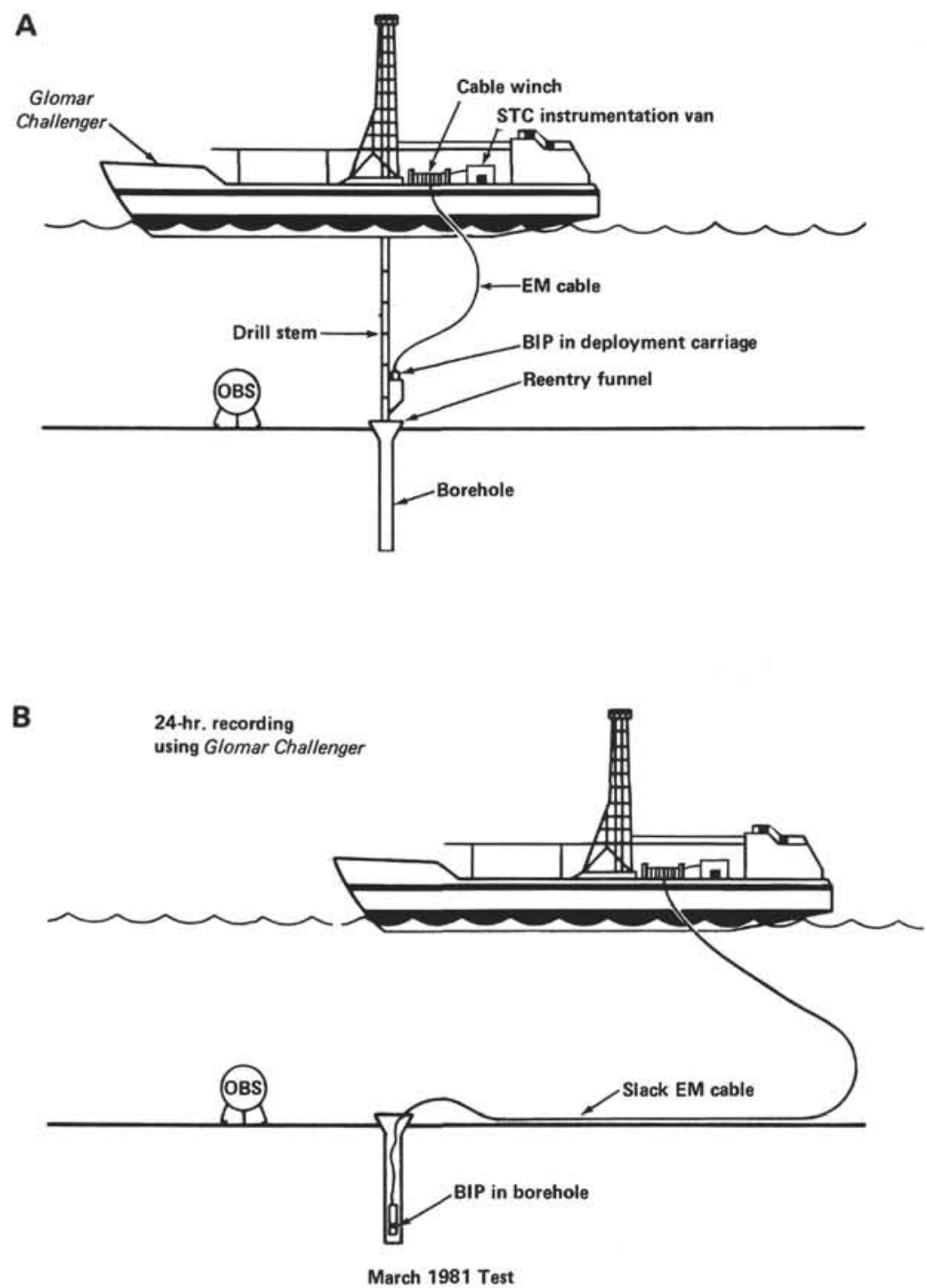

Figure 1. Marine Seismic System (MSS) in (A) deployment and (B) operational configurations. The cable winch was installed midship almost directly under the derrick. The ship was offset $980 \mathrm{~m}$ from the borehole, and $1330 \mathrm{~m}$ of cable was slacked.

search]-13) deployed vector averaging current meters approximately 10,100 , and $1000 \mathrm{~m}$ above the ocean bottom near the hole. In addition, the Lynch lowered a direct reading acoustic current meter to selected intervals between the surface and $1000 \mathrm{~m}$ to provide real-time current data. These data could be used to correct cable tension, ship heading, and pay-out speed and to maintain the cable catenary in the preferred direction.

3 . Would sensors monitoring the state of health of the tool indicate that it was performing within design limits in a borehole environment? The sensor package was equipped with temperature sensors at various locations to monitor temperatures in the borehole package. These sensors also may be used to provide a long-term measure of temperature fluctuations in the borehole. In addition, a pressure sensor was located in the atmosphere around the electronics. Other functions monitored concurrently with seismometer and accelerometer outputs included voltage and current levels, carrier frequencies, and the voltage applied to the seismometer calibration circuits.

4. How do borehole seismometer signal and noise levels compare with similar signals recorded on conventional ocean bottom seismometer (OBS) records? A fundamental assumption of the MSS program was that a subseafloor seismometer would achieve higher signal to noise levels than borehole SRO stations on land. By monitoring the borehole noise levels and comparing them with land SRO and with OBS levels, it should be possible to assess the level of ambient noise in the seafloor, the damping of noise induced by the sediment cover, and the improvement achieved by borehole installation. 


\section{MSS INSTRUMENTATION}

\section{System Description}

The Marine Seismic System consists of two functional subsystems. These are the Borehole Instrumentation Package (BIP) and the Shipboard Test Console (STC) (Fig. 2). The STC powers the BIP, records and monitors data, and displays selected data and state-of-health information in real time. The BIP and STC are connected by an armored electromechanical (EM) cable and slip ring assembly on an EM cable winch. DC power is applied to the BIP, and digital data are transmitted to the STC via this cable.

\section{The Borehole Instrument Package (BIP)}

The BIP, Teledyne Geotech Model 53100 , is an assemblage of acceleration, seismic, temperature, pressure, and state-of-health sensors, and associated signal conditioning and control electronics. Figure 3 shows the mechanical layout of the various components in the BIP and illustrates component locations.

The accelerometers consist of two sets of three component orthogonal sensors, the output from each being preconditioned by a charge amplifier and an anti-aliasing filter. The peak acceleration is $50 \mathrm{~g}$ for all channels except for the $2 \mathrm{Z}$ axis channel, which has a peak accel- eration of $100 \mathrm{~g}$. The seismic sensor system consists of two Teledyne Geotech S-700 short-period, vertical-axis, piezoelectric-type seismometers and associated frequency filters necessary to provide the desired response shaping as well as anti-aliasing. Each seismometer drives three frequency filters. The voltage gains are staggered such that a total dynamic range of $144 \mathrm{~dB}$ is achieved, with an overlap of $30 \mathrm{~dB}$ between adjacent channels as shown in Figure 4. Figure 5 is a normalized seismic channel frequency response curve.

Four temperature sensors are provided, each having a range of 0 to $100^{\circ} \mathrm{C}$. The temperature sensors are attached to the BIP DC-to-DC converter, near the midportion of the electronics stack, near the bottom of the electronics stack, and near the bottom of the seismometer package. The lower sensor quickly stabilized and provided a long-term record of borehole temperature.

A pressure sensor with an output range of 0 to 40 psia (pounds per square inches of air) is located in the electronics stack to measure the internal pressure of the BIP. The BIP is evacuated and backfilled with helium to a nominal 16 PSIA during final assembly.

The BIP state-of-health ( $\mathrm{SOH})$ monitors are provided to monitor internal conditions and to assist in any system fault analysis. These devices include voltage monitors for the accelerometer filter and charge amplifier

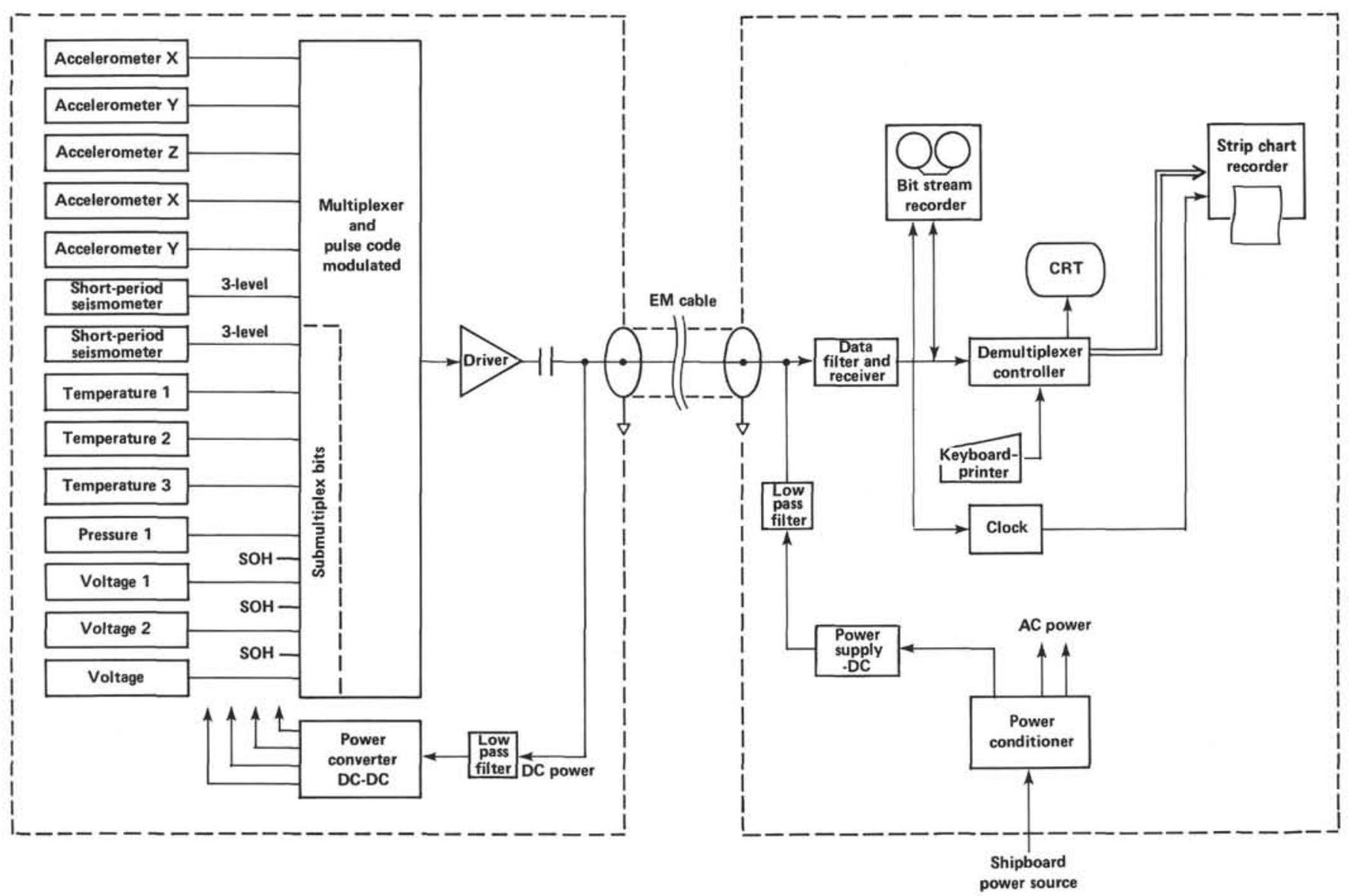

Figure 2. Functional block diagram of borehole instrument package (BIP) (left) and shipboard test console (STC) (right). The EM cable connecting the two instrument subsystems is about $9 \mathrm{~km}$ in length. ( $\mathrm{SOH}=$ state of health; 3 -level indicates 3 gain bands for the recording.) 


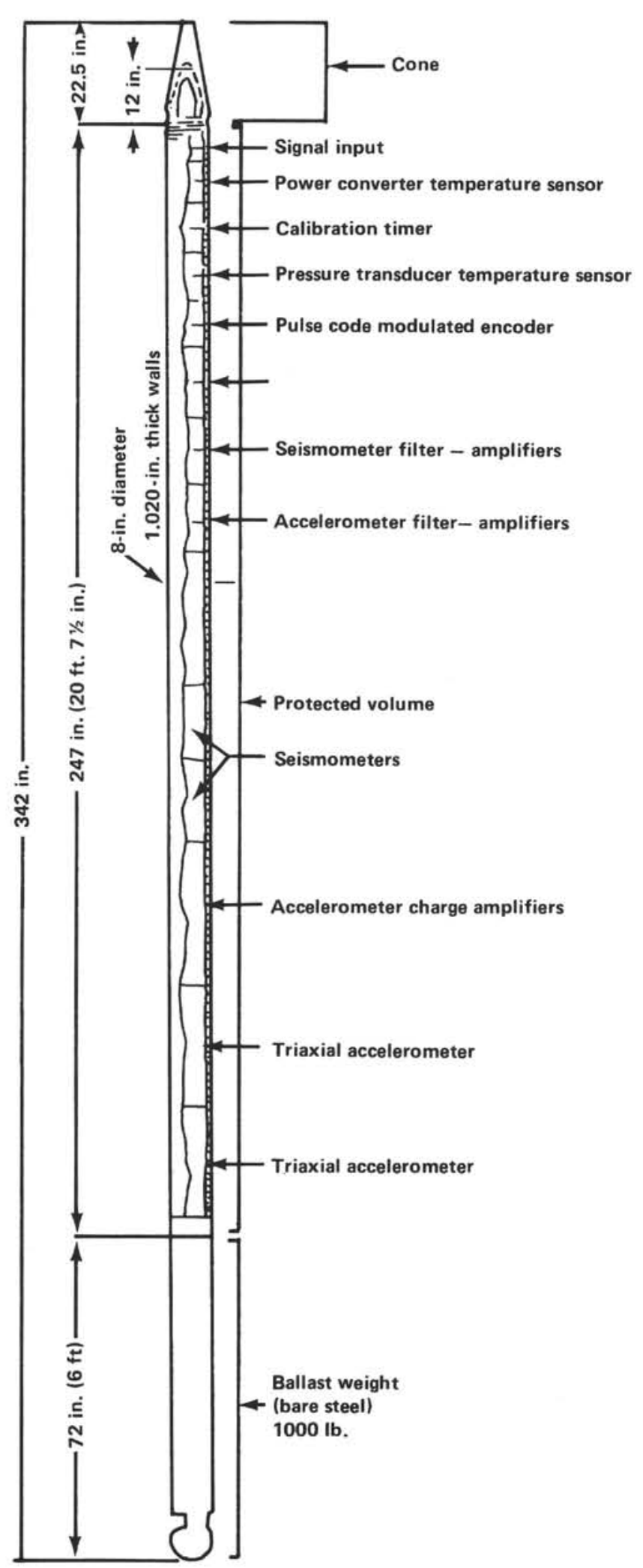

Figure 3. BIP mechanical layout illustrating dimensions of components and locations of subassemblies. This configuration retains space for the long-period seismometers to be added later.

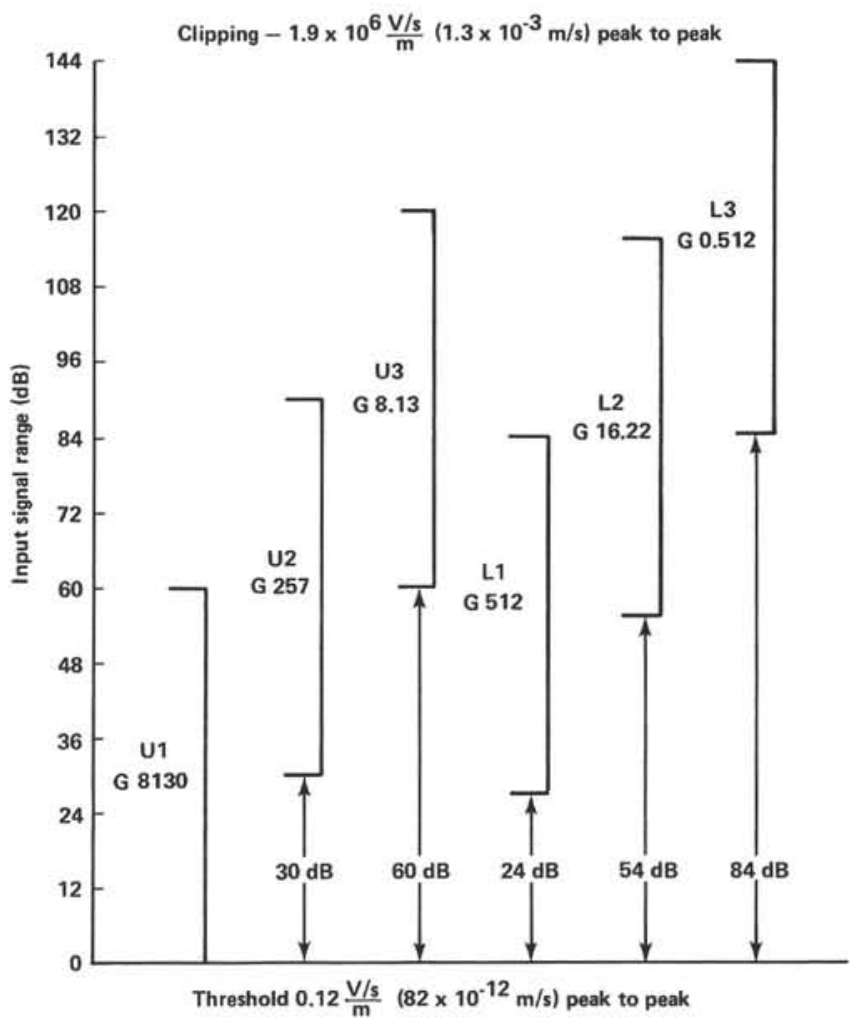

Figure 4. Dynamic gain-ranging format used for the BIP. The $\mathrm{L}$ and $\mathrm{U}$ designators refer to seismometer positions in the BIP. $G=$ filter voltage gain.

power supplies, the seismometer filters, the bipolar ( \pm 12 VDC) supplies for the two S-700 seismometers, the BIP temperature sensor bridge reference voltage, the BIP 150 VDC input voltage, and a negative (when active) monitor for the seismic channel calibration circuit output.

The data from the sensor and state-of-health channels are input as analog signals to a pulse code modulated (PCM) encoder, which time-division multiplexes and digitizes the data, then formats and outputs the data as a 54-kHz PCM digital data stream, with appended synchronization data. Three levels of subcommutation are used to permit the desired sampling rates for the various data types. Figure 6 illustrates the PCM data format.

The output of the PCM encoder is preconditioned by a PCM amplifier for transmission via the EM cable. This circuit card also separates the high voltage DC component on the cable providing power to the BIP (150 VDC). This input DC is converted to the various voltages required by the subassemblies by a DC-to-DC converter module. The outputs of this device are further conditioned via outboard current-limited series regulators that isolate the converter from external subassembly failures, thereby minimizing the risk of catastrophic system failures caused by minor module failures.

\section{The Shipboard Test Console (STC)}

The STC is an assemblage of primarily off-the-shelf commercial data decoders, timers, and recorders mounted in standard relay racks in an $8 \times 12 \mathrm{ft}$. environmentally 


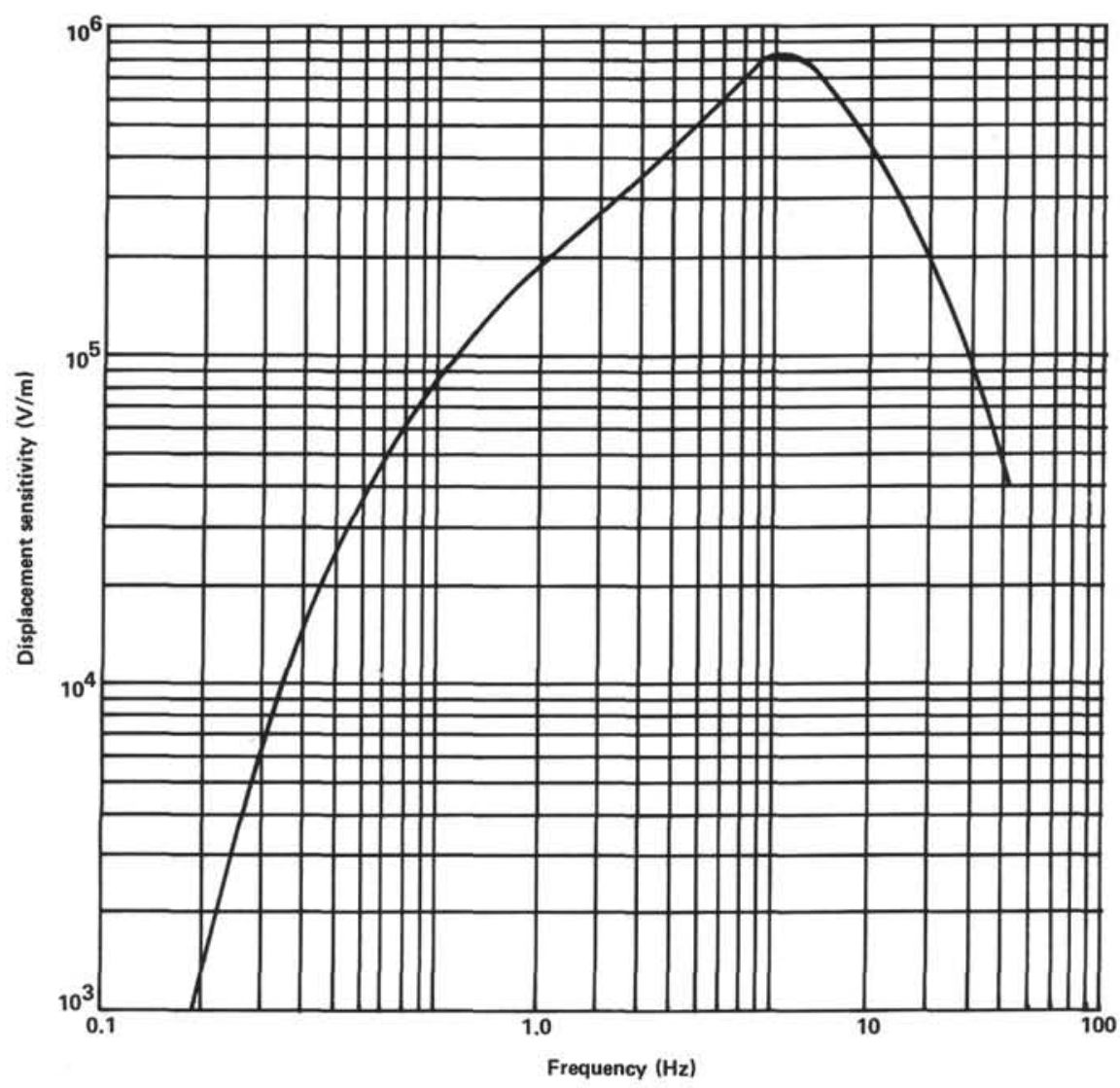

Figure 5. Response curve for Teledyne Geotech S-700 short-period, vertical seismometers used in BIP.

controlled equipment van. The major functional items of the STC are: a specially built line receiver, two tape recorders (Ampex, Model PR-2230), two decommutators (Aydin Vector, Model PLD-400; Conic D-Pad III), a time code generator-translator (Datum, Model 9300-100), three strip chart recorders (Hewlett Packard, Model 7404, 4-channel), a teletypewriter (Texas Instruments, Model KSR 743), a specially built patch panel, four power supplies (Kepco, Model OPS 100-1m), and two uninterruptable power systems (UPS) (Topaz, Model 82102-12 with battery modules Model 2566-2).

Pulse code modulated (PCM) data are received from the BIP via the receiver, preconditioned, then applied in parallel to each of the two magnetic tape machines (ana$\log 14$ track) and to each of the two data decommutators. The raw PCM data and an Inter-Range Instrumentation Group Format B (IRIG B) time signal generated by the time code generator-translator are recorded on magnetic tape. Through the use of a "stitch back" mode and a modification allowing the activation or deactivation of selected record heads (tracks), the data are recorded in 7 passes. Each pass, at $33 / 4$ in./s, will accommodate approximately $31 / 2 \mathrm{hr}$. of $50 \mathrm{kHz}$ digital data.

The two PCM data decommutators allow real-time monitoring of both the data and the state of health $(\mathrm{SOH})$ of the BIP. The Conic D-Pad III uses a CRT display and 12 user programmable digital to analog (D/A) output ports to display and make available to external recorders the data and SOH information. Hard copy output of any CRT display is available upon operator request via the teleprinter. All D/A output ports are hardwired to the patch panel where they can be patched to any of 12 strip chart channels. The Aydin Vector PLD-400 device is limited to 12 firmware programmed D/A ports and one front panel D/A port, the input of which is operator selectable via front panel switches.

Three analog strip chart recorders are provided for recording up to a total of 12 channels of real-time or playback analog data. Each recorder has an additional edge marker pen for use as a time or event marker. A time code was normally applied to the input of this channel.

The time code generator-translator puts out an IRIG B time code (Julian day, hours, minutes, and seconds) in the generator mode for recording on magnetic tape. An additional output is fed to the marker pens of the strip chart recorders. In the translate mode, the timer serves as a time code reader for off-line tape playback. The time code generator was synchronized to WWV for accurate time measurements.

The BIP power supply system consists of redundant sets of series-connected DC power supplies providing $300 \mathrm{~mA}$ (maximum) at 150 VDC. A front panel switch is provided to select the back-up power supply set in the event of a failure. 


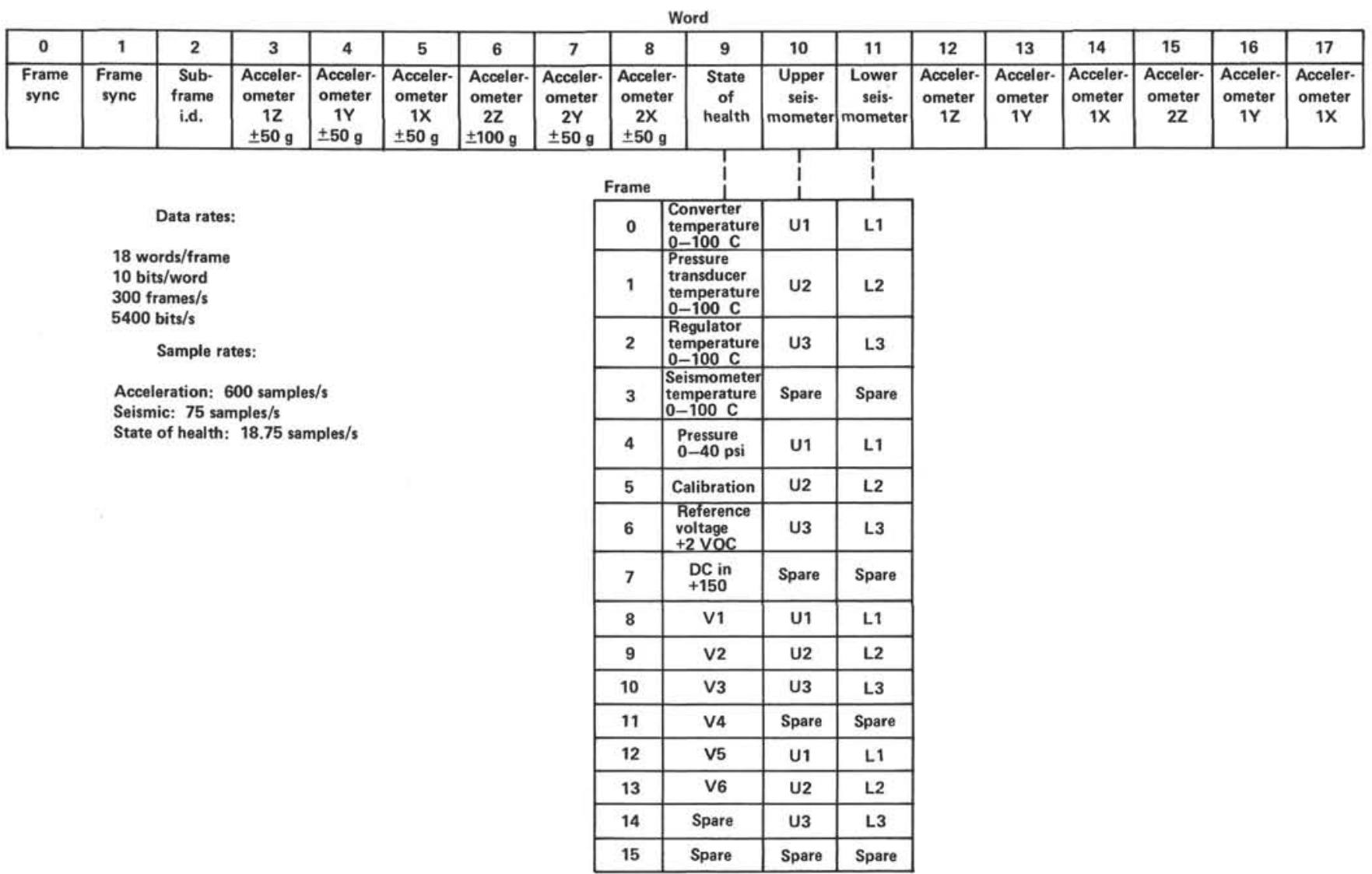

Figure 6. PCM data format, data rates, and samples rates used during Leg 78B MSS test.

The STC technical system power is supplied by two uninterruptable power systems to isolate the technical load from ships' power surges and to provide up to $19 \mathrm{~min}$. of stable power in the event of a total loss of ships' AC power.

\section{OPERATIONAL ANALYSIS}

During previous borehole seismometer experiments involving the Glomar Challenger, the tool has always been lowered through the drill string (e.g., Stephen et al., 1980; Duennebier et al., 1983). Because of the large diameter of the BIP, it was necessary to design a means for lowering the tool to the seafloor in a carriage external to the pipe, which would leave the pipe clear for the passage of the reentry tools. Once the cone has been located and reentered, the BIP could be hydraulically shunted in line below the pipe and lowered down the hole. To insure the success of future applications of the technique, it is necessary to evaluate the equipment and deployment procedures used on Leg $78 \mathrm{~B}$, to analyze the dynamic loading experienced by the seismometers during deployment, and the cable tensions recorded during the experiment. In addition, a brief summary of a theoretical study of the dynamic and static response of a suspended cable due to current and ship motion is included for comparison (see the Appendix).

The deployment equipment used on Leg 78B (Fig. 7) consists, from the top down, of a carriage control sub, a carriage sub, and a stinger. The carriage control sub is attached directly to the lower end of the bottom-hole assembly and contains the hydraulic control ports and seats for a Baker plug that seals the system in order to permit the alignment of the BIP with the borehole after reentry has been achieved. The carriage sub houses the BIP outside the drill string as it is lowered to the seafloor and during reentry. The stinger serves as a guide for the BIP once it has been lowered into the throat of the casing. Both the carriage sub and the stinger are fitted with 1.25-in. cable exit slots throughout their entire length.

\section{Assembly and Initial Lowering}

The assembly a sequence and initial lowering of the reentry sub was initiated by the keelhauling the EM cable and tying it off at the moon pool. After the stinger was run through the rotary table and landed on the slips, the carriage assembly was lifted on traveling blocks, lowered and aligned with the stinger flange, and attached (Fig. 8). The total assembly was then lowered through the rotary table and hung on drill collar slips and safety clamps while the assembly bolts were tack welded to prevent loosening during deployment. After the welding was completed, four 5 -ft. stroke, 8.25 -in. O.D. Baash-Ross bumper subs, each weighing $1800 \mathrm{lb}$., were attached to the carriage control sub and the tool joints torqued to API (American Petroleum Institute) specifications. The total reentry assembly was then suspended on the traveling block while the drill collar slips 


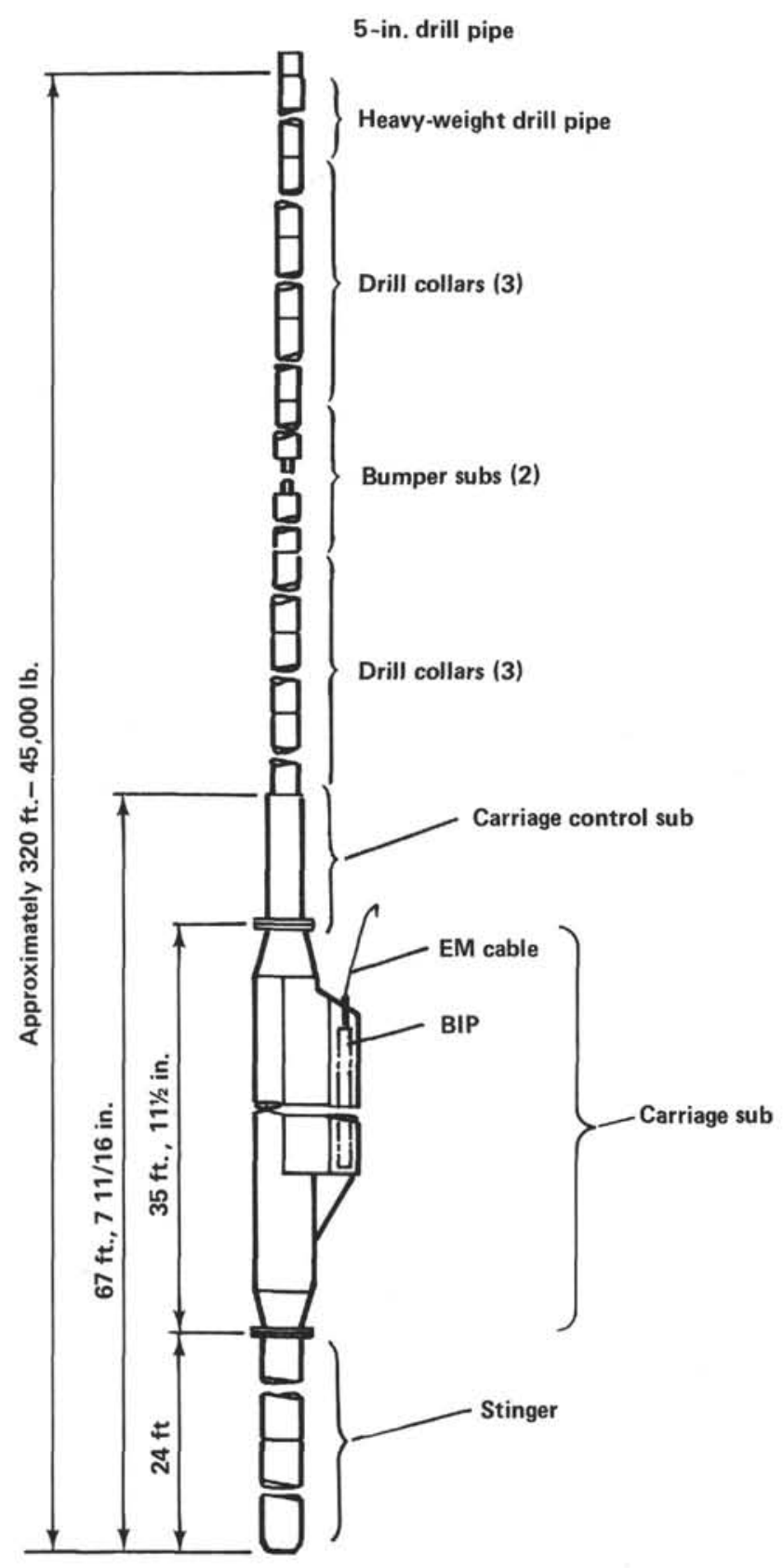

Figure 7. Reentry sub assembly used on Leg 78B for BIP reentry and deployment. Cable exit slot extends from top of BIP container to lower end of stinger. .

were removed. Once the slips had been removed, tugger and cat lines were used to snub the assembly forward on the rotary table while the cable was passed through and rigged on a sheave hanging from a tugger line. The BIP was then moved to the catwalk, the cable connected, and system checks completed. After checking the electronics, the carriage assembly was lifted until the top of the carriage was approximately $3 \mathrm{ft}$. above the rotary table. The BIP was then picked up with both the crane and a tugger until the load could be taken vertically on the cable for lowering into the carriage control sub. At this point, carrier shear pins and hydraulic lines were in- stalled from the moon pool work platform, and the total reentry assembly was lowered approximately $20 \mathrm{ft}$. and snubbed with tugger and cat lines. The cable bight on the rig floor was then removed from the sheave, carefully passed through the rotary table, and secured on the moon pool work platform. After the assembly was lowered and hung on the slips, one 30 -ft. section of 7.25 -in. O.D. drill collar, weighing $3000 \mathrm{lb}$., was attached to the bumper sub; this assembly was lowered and one stand of drill pipe attached to the drill collar. During this operation, the carriage assembly cable exit slot was oriented facing the A-frame sheave, and orientation marks were scribed on both the rotary table and the tool joint; this orientation was maintained throughout the pipe lowering. The pipe was then lowered $30 \mathrm{ft}$., and the cable bight carefully passed through the piccolo base and released. At $360 \mathrm{~m}$ depth, the line counters were set to correspond to the assembly measurements, the weight indicators were checked, the recorders were started, the heave compensator was raised to mid-stroke, and slow but normal pipe tripping was begun.

The cable was not tensioned for the first $360 \mathrm{~m}$ of lowering, but the tension was increased to $500 \mathrm{lb}$. at a depth of $615 \mathrm{~m}$ and to $3000 \mathrm{lb}$. at a depth of $898 \mathrm{~m}$. The tensions used were lower than planned because the current's effects on the cable and drill pipe were less than expected. Cable tensions were increased to a maximum of $7200 \mathrm{lb}$. at a total depth of $4488 \mathrm{~m}$. The total time required to lower the reentry sub to within $3 \mathrm{~m}$ of the reentry cone was $17 \mathrm{hr}$.

Initial concerns during the lowering were pipe orientation, cable entanglement, and coordination between the driller and the winch operator. Pipe orientation and driller-winch operator coordination proved to be no problem because of the skill and attention of the drilling crew. Cable entanglement did not develop because of careful attention to cable tension and pipe orientation as well as the apparent absence of currents sufficient to affect the drill pipe or the cable.

\section{Reentry}

At 2200Z, March 27, the reentry sonar was lowered on the logging wire and scanning initiated. The cone was located and reentry was smoothly completed after about 1.5 hrs. From about $2 \mathrm{~m}$ above the cone, the reentry sub was stabbed for a distance of about $7.5 \mathrm{~m}$ at a rate of about $1.8 \mathrm{~m} / \mathrm{s}$, then slowly lowered $(0.3-0.6 \mathrm{~m} / \mathrm{s})$ an additional $10 \mathrm{~m}$. The sonar tool was recovered and the line counters reset to correspond with the amount of drill pipe and bottom-hole assembly deployed. Cable tension was decreased to $7000 \mathrm{lb}$. in order to carry about half the weight of the instrument package and allow the instrument to fall a short distance when the carriage pins were sheared.

While the bottom-hole assembly was in the reentry cone, an Otis-Baker tool was run down on the sand line to retrieve and latch the pressure seal plug into the carriage control sub. When this step was accomplished and the sand line withdrawn, hydrostatic pressure was increased to 2500 psi with the cement pump. At 2500 psi, the accelerometer output indicated that the carriage 


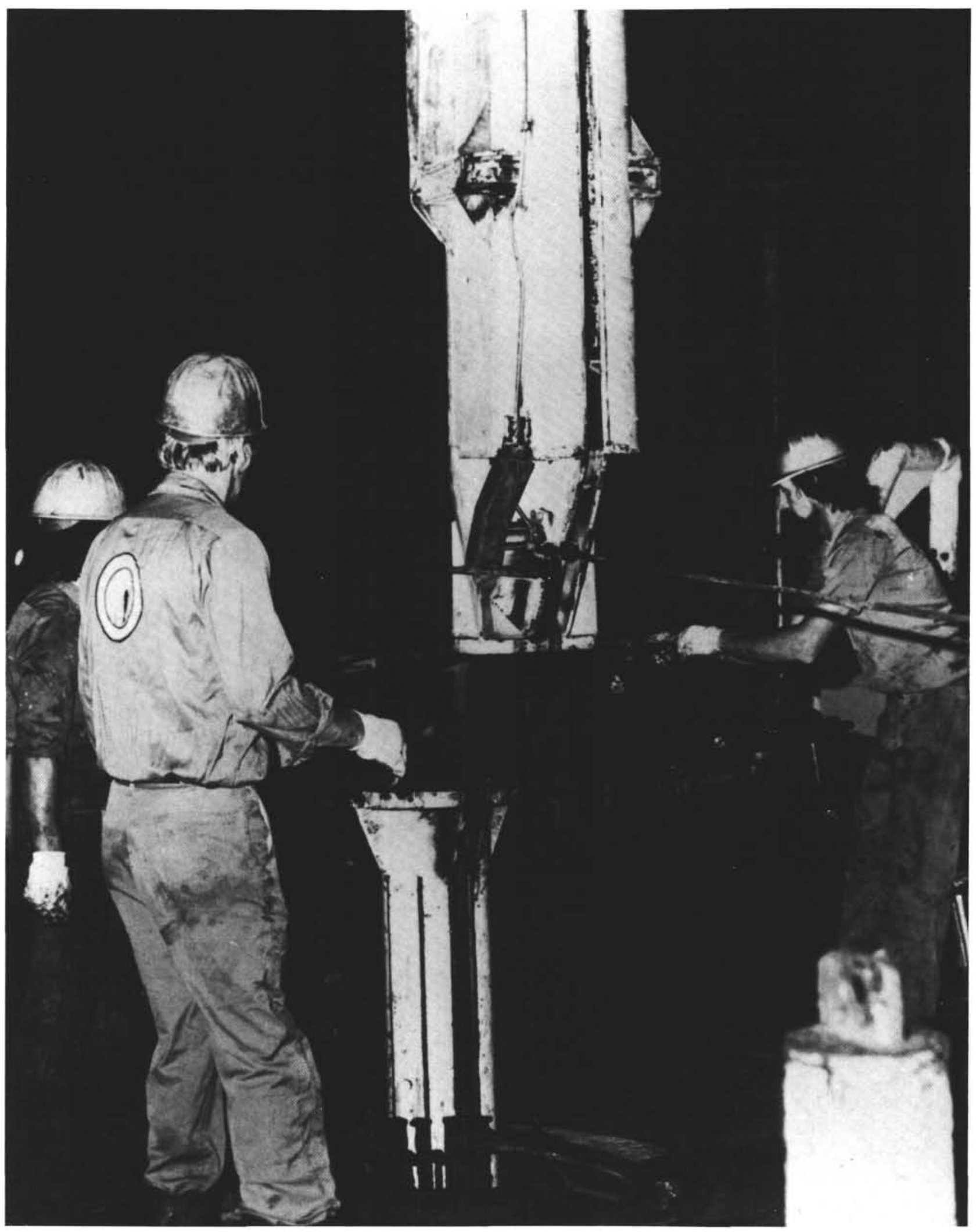

Figure 8. Drilling crew aligning cable exit slots on carriage sub and stinger prior to assembly. 
control pins had sheared and moved the BIP into the lowering position; however, the pressure gauges and dynamometers did not initially confirm this result. After a few moments, the winch began paying out cable and the dynamometers stabilized. The instrument package was then lowered to the bottom ( $5094 \mathrm{~m}$ below sea level; $609 \mathrm{~m}$ sub-bottom) while accelerations were being recorded. After this, the BIP was raised $300 \mathrm{~m}$ to about $4800 \mathrm{~m}$ and held suspended while the ship was moved about $60 \mathrm{~m}$ up-current. Then the assembly was raised so that the reentry stinger was about $20 \mathrm{~m}$ above the reentry cone before the pressure seals were hydrostatically ruptured and the cable gate opened. Although the cement pump pressurized the pipe to $3400 \mathrm{psi}$, no evidence of gate seal rupture was recorded on board the Challenger. The accelerometers indicated minimal motion while 20 stands $(1800 \mathrm{ft}$.) of drill pipe were carefully retrieved. At this time, it was concluded that entanglement had not occurred, so the BIP was lowered to the bottom of the borehole. The running drill string was pulled up and the carriage assembly retrieved, disassembled, and returned to storage.

The ship was then allowed to drift about a kilometer down wind while an additional $600 \mathrm{~m}$ of cable were deployed to evaluate the importance of ship-generated noise. Prior to commencing the shooting program, an additional $730 \mathrm{~m}$ of cable were deployed to help isolate the BIP from ship-generated noise.

\section{Instrument Recovery}

After completion of the shooting program at $0200 \mathrm{Z}$, March 30, the borehole instrument was recovered, first by recovering the slack cable from the ocean floor and then by reeling additional cable as the ship was moved over the cone with the cable tension maintained at approximately $3000 \mathrm{lb}$. When the ship was very nearly over the cone, and an attempt was made to pull straight up on the BIP, the load cell measured $16,500 \mathrm{lb}$. $(8500 \mathrm{lb}$. over the weight of the BIP plus cable), with little movement indicated by the accelerometers. After moving the ship approximately $60 \mathrm{~m}$ east and slacking $10 \mathrm{~m}$ of cable, we commenced recovering cable and received instant confirmation that the instrument was free of the bottom. We then continued recovering the cable until the BIP surfaced, at which point we attached a crane line to the tool and lifted it on board after an elapsed time of $74 \mathrm{hr}$. and $45 \mathrm{~min}$.

The cause of the sudden increase in cable tension when we first tried to pull the tool out of the hole is not known. Either the cable was fouled by a sonar reflector on the reentry cone or the recovery angle was not straight out of the hole. Alternatively, the instrument may simply have settled into the mud and required a good tug to release. Subsequent examination of the cable revealed an abraided section $610 \mathrm{~m}$ above the termination, suggesting fouling by a sonar reflector.

\section{Dynamic Loading on BIP during Deployment}

In order to determine the magnitude of impact loading that seismometers are likely to register during a normal reentry and borehole deployment, the prototype BIP was equipped with triaxial accelerometers that were continuously recorded during deployment. The accelerometers were installed on $12.7-\mathrm{cm}$-diameter tube segments bolted approximately 25 and $50 \mathrm{~cm}$ above the base of the pressure vessel. These tubes were fixed at the base and laterally spring-stabilized approximately $2 \mathrm{~m}$ above the base. Thus the mountings were much more rigid longitudinally than laterally. The following is a brief description and a preliminary analysis of the accelerations recorded for each phase of the deployment.

Loading the BIP into the reentry sub. The steps analyzed included removing the BIP from its shipping container, standing it upright, and inserting it into the carriage housing on the rig floor. The maximum impacts measured were $4.2 \mathrm{~g}$ on the $\mathrm{X}$-axis due to striking the rig floor during the process of lifting the instrument upright.

Lowering the reentry assembly to the seafloor. Accelerations were recorded while drill pipe was added to the string and lowered; cable was simultaneously paid out at a rate that maintained a relatively constant tension on the BIP. Vertical accelerations were recorded each time pipe was added to the drill string. The maximum readings were about $2 \mathrm{~g}$, which attenuated with increasing drill string length.

Reentry into the cone and cased borehole. Accelerations were recorded when the stinger was stabbed into the cone from about $2 \mathrm{~m}$ above the cone, as it was lowered quickly for another $7.5 \mathrm{~m}$, and then as it was lowered more slowly for an additional $10 \mathrm{~m}$ to ensure that the stinger was fully in the upper hole casing. The first contact with the cone produced an impact of about $6 \mathrm{~g}$ (Fig. 9); subsequent impacts were smaller, indicating that the bumper subs were operating. The predominant $\mathrm{X}$ axis frequency was about 40 to $50 \mathrm{~Hz}$ while the Y-axis frequency was in the 80 to $90 \mathrm{~Hz}$ range. The major vertical shock impulse lasted approximately $15 \mathrm{~ms}$. The stab speed for the initial $7.5 \mathrm{~m}$ was estimated at about $1.8 \mathrm{~m} / \mathrm{s}$ $(6 \mathrm{ft} . / \mathrm{s})$ while that in the following $10 \mathrm{~m}$ was estimated at 0.3 to $0.6 \mathrm{~m} / \mathrm{s}(1-2 \mathrm{ft} . / \mathrm{s})$. A sharp horizontal shock followed immediately by a vertical shock may have occurred as the stinger skidded into the bottom of the cone.

Reentry assembly standing in cone. Accelerations imparted to the reentry assembly during the 6-hr. period required to retrieve the sonar tool and run in and latch the Baker plug appeared to occur in 4.5- to 6.5-s periods roughly coinciding with ship and drill string motion. Typically, these motions are a small $(0.5 \mathrm{~g})$ vertical acceleration followed by larger $(1 \mathrm{~g})$ horizontal accelerations, probably due to opening or closing of the bumper subs.

BIP carriage shift and release. Shifting the BIP horizontally $28 \mathrm{~cm}$ in order to align the BIP over the borehole produced accelerations of about $5 \mathrm{~g}$ for about $0.8 \mathrm{~s}$ on the horizontal axis and smaller accelerations for $0.25 \mathrm{~s}$ on the vertical axis (Fig. 10). The accelerometers continued to show motion for several seconds on the horizontal axes, indicating resonance within the BIP base or the reentry assembly or both. The predominant lateral frequency appeared to be in the 50 to $60 \mathrm{~Hz}$ range, with the $\mathrm{X}$-axis indicating slightly lower frequencies but higher amplitudes than the Y-axis. 

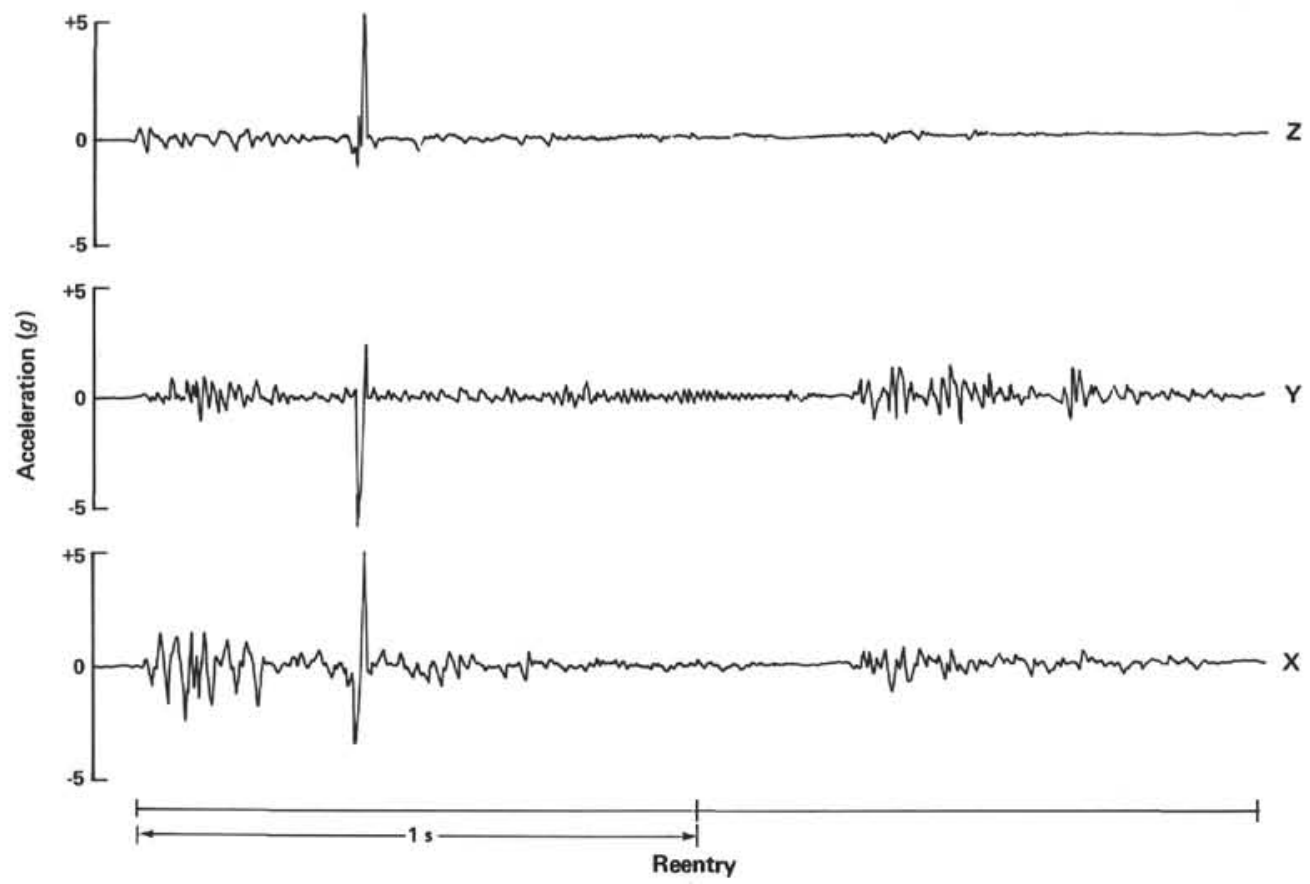

Figure 9. Accelerations recorded during reentry. The Y-axis accelerometer response prior to the X-axis response may be an artifact of installation.

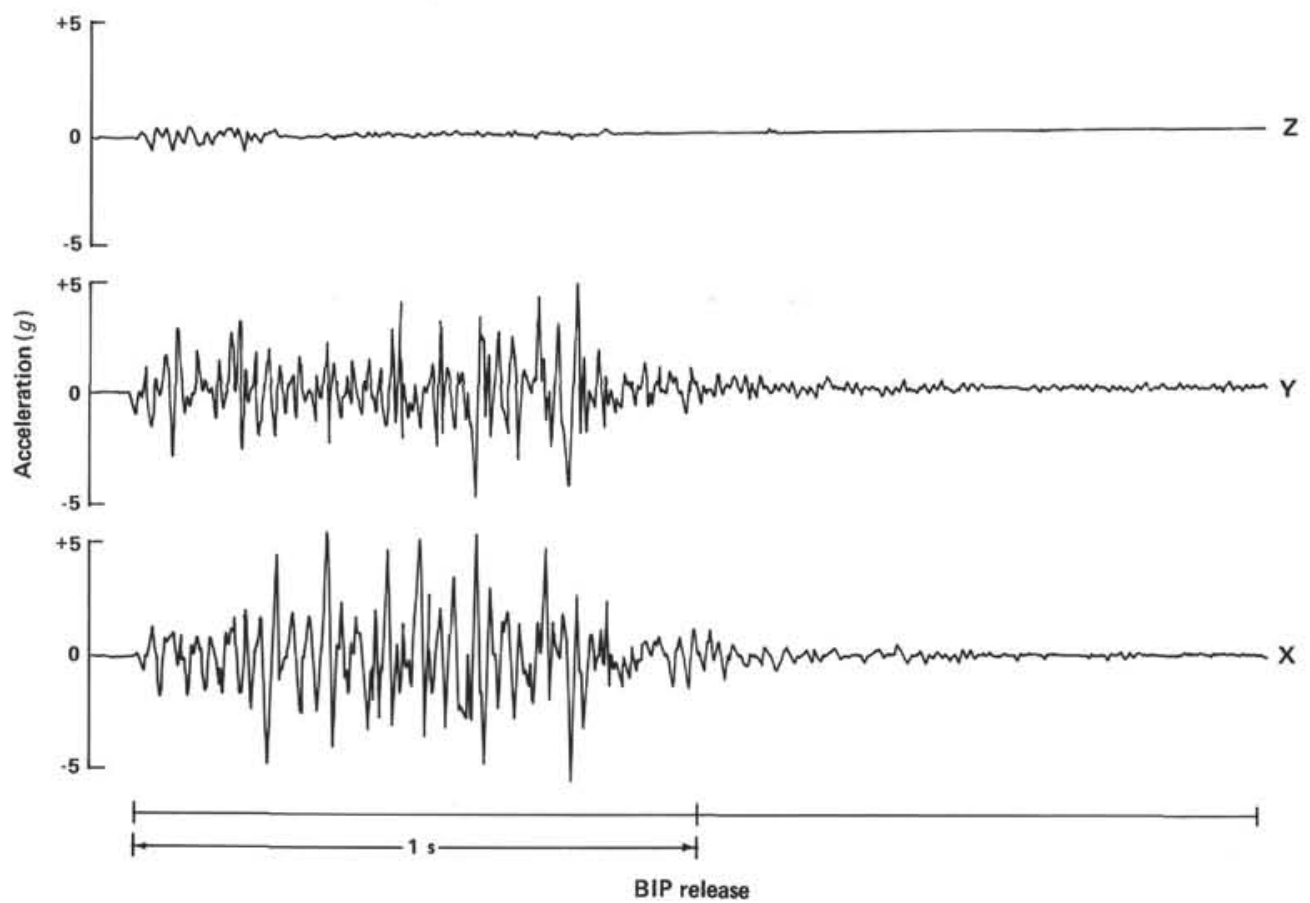

Figure 10. Accelerations recorded when the BIP was shifted from the carrying position to the release position. Accelerometer outputs were the most positive indication of BIP release.

Lowering the BIP in the borehole. Irregularities in the borehole imparted shocks to the instrument housing. These shocks (maximum $4 \mathrm{~g}$ ) were probably caused by the BIP striking rock ledges and rebounding. They were not considered a serious threat to the safety of the instrument.
Landing the BIP at the bottom of the borehole. When the BIP contacted the bottom of the borehole, large vertical accelerations were expected. The peak vertical acceleration was less than $3 \mathrm{~g}$. Horizontal accelerations, however, were higher than expected (Fig. 11), indicating that the BIP shifted horizontally as it reached the bot- 


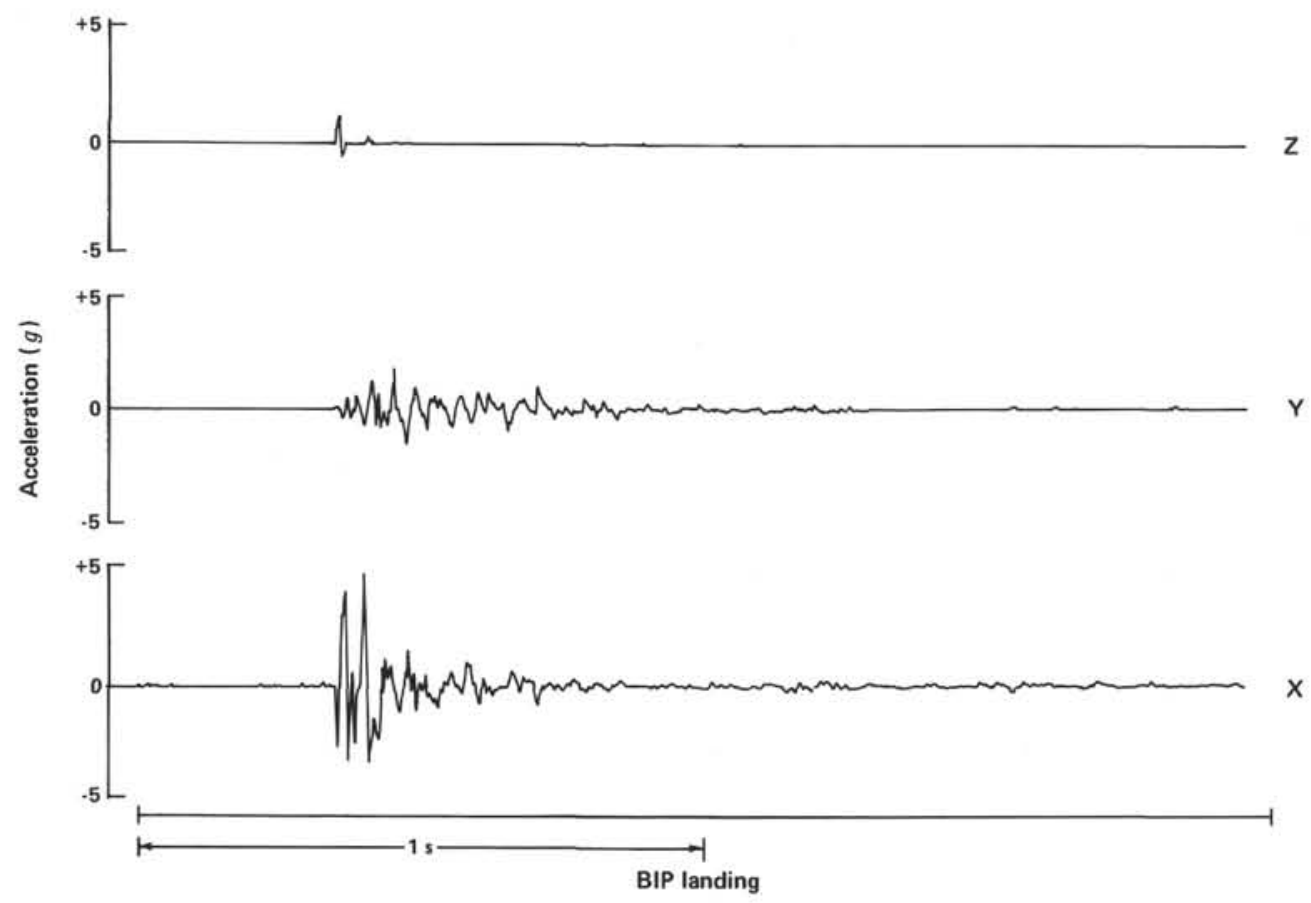

Figure 11. Accelerations registered when the BIP touched down at the bottom of the borehole.

tom. The horizontal accelerations may have been caused by the BIP tilting over and striking the side of the borehole.

Lifting the BIP. Recovery of the BIP caused shocks because of the forces required to free the instrument and irregularities in the borehole walls. These accelerations were within expected ranges.

In summary, the reentry accelerations were less than expected, but other accelerations were within the predicted ranges. The horizontal axes (X-axis in particular) may have recorded slightly magnified accelerations due to mounting characteristics. Improved shock isolation would undoubtedly be necessary for the more adverse weather conditions likely to be encountered in higher latitudes.

\section{Cable Control}

Proper cable tension was deemed necessary to avoid cable-drill pipe entanglement during deployment. Cable tension adjustments were derived from a mathematical model that allowed variable current forces, end tensions, end positions, and cable wet weight as inputs. A program to derive these factors-CABLE T-was prepared for an HP-41 CV calculator.

Static tensioning analyses were run for a cable with a wet weight of $0.432 \mathrm{~kg} / \mathrm{m}$ in $52-\mathrm{cm} / \mathrm{s}(1 \mathrm{knot})$ and $26-\mathrm{cm} / \mathrm{s}$ surface currents decreasing monotonically with depth. Table 2 provides the resultant characteristics for a range of cable tensions during a $4572-\mathrm{m}(15,000-\mathrm{ft}$.) deployment. At these deployment depths, cable elongation roughly accommodates the catenary caused by the current. Table 3 shows the effect on a fixed cable length of a surface current of up to a $105 \mathrm{~cm} / \mathrm{s}$ (2 knots). A deployment tension chart (Fig. 12) was prepared as a guide to cable pay out and tensioning. These cable tensions
Table 2. Leg 78B, Hole 395A cable tensioning characteristics, 15,000ft. deployment.

\begin{tabular}{|c|c|c|c|c|c|c|c|c|c|c|}
\hline \multirow{2}{*}{$\begin{array}{c}\text { Cable } \\
\text { tension (lb.) }\end{array}$} & \multicolumn{4}{|c|}{1 knot surface current } & \multirow[b]{2}{*}{$T_{\min }}$. & \multicolumn{4}{|c|}{0.5 knot surface current } & \multirow[b]{2}{*}{$T_{\min }$} \\
\hline & $Y$ & L & $\Delta$ & $L^{1}$ & & $\mathbf{Y}$ & L & $\Delta$ & $L^{1}$ & \\
\hline 5000 & 1201 & 15,316 & 20 & 15,296 & 371 & 308 & 15,016 & 21 & 14,995 & 570 \\
\hline 6000 & 782 & 15,111 & 28 & 15,083 & 1510 & 228 & 15,008 & 28 & 14,978 & 1572 \\
\hline 7000 & 614 & 15,065 & 36 & 15,029 & 2614 & 178 & 15,004 & 36 & 14,968 & 2573 \\
\hline 8000 & 509 & 15,043 & 43 & 15,000 & 3518 & 159 & 15,003 & 43 & 14,960 & 3573 \\
\hline 9000 & 436 & 15,031 & 51 & 14,980 & 4536 & 144 & 15,002 & 51 & 14,951 & 4573 \\
\hline 10000 & 384 & 15,023 & 58 & 14,965 & 5543 & 132 & 15,001 & 58 & 14,943 & 5573 \\
\hline
\end{tabular}

Note: $\mathrm{Y}=$ lateral displacement (ft.), $\mathrm{L}=$ cable length (ft.), $\Delta=$ elongation (ft.), $\mathrm{L}^{1}=$ corrected cable length (ft.), and $T_{\min }=$ tension at bottom of cable (lb.).

Table 3. Cable tension versus current velocity on a cable of fixed length.

\begin{tabular}{rrrcrrr}
\hline $\begin{array}{c}\text { Current } \\
\text { velocity } \\
\text { (knots) }\end{array}$ & $\begin{array}{c}T_{0} \\
\text { (lb.) }\end{array}$ & $\begin{array}{c}\mathrm{Y}_{\max } \\
\text { (ft.) }\end{array}$ & $\begin{array}{c}L \\
\text { (ft.) }\end{array}$ & $\begin{array}{c}\Delta \\
\text { (ft.) }\end{array}$ & $\begin{array}{c}L^{1} \\
\text { (ft.) }\end{array}$ & $\begin{array}{r}T_{\min } \\
\text { (lb.) }\end{array}$ \\
\hline 0.1 & 4426 & 93 & 15,020 & 20 & 15,000 & 3 \\
0.5 & 4984 & 331 & 15,021 & 21 & 15,000 & 555 \\
1.0 & 8000 & 509 & 15,043 & 43 & 15,000 & 3,518 \\
1.5 & 12,000 & 650 & 15,074 & 74 & 15,000 & 7,822 \\
2.0 & 17,100 & 796 & 15,109 & 109 & 15,000 & 12,490 \\
\hline
\end{tabular}

$\mathrm{T}_{0}=$ tension at top of the cable, $\mathrm{Y}_{\max }=$ maximum lateral displacement, $\mathrm{L}=$ cable length, $\Delta=$ elongation, $\mathrm{L}^{1}=$ corrected cable length, $T_{\min }$. $=$ tension at bottom of cable.

could be approximately correlated with average load cell readouts by multiplying by a factor of 1.78 . Unfortunately, the 1.78 correction factor was unique to this installation because of variations with both the load and the heave compensator position.

Experimental data were derived both from the hydraulic load cell digital readout and from analog records. Relatively high oscillatory loads induced by ship motion 


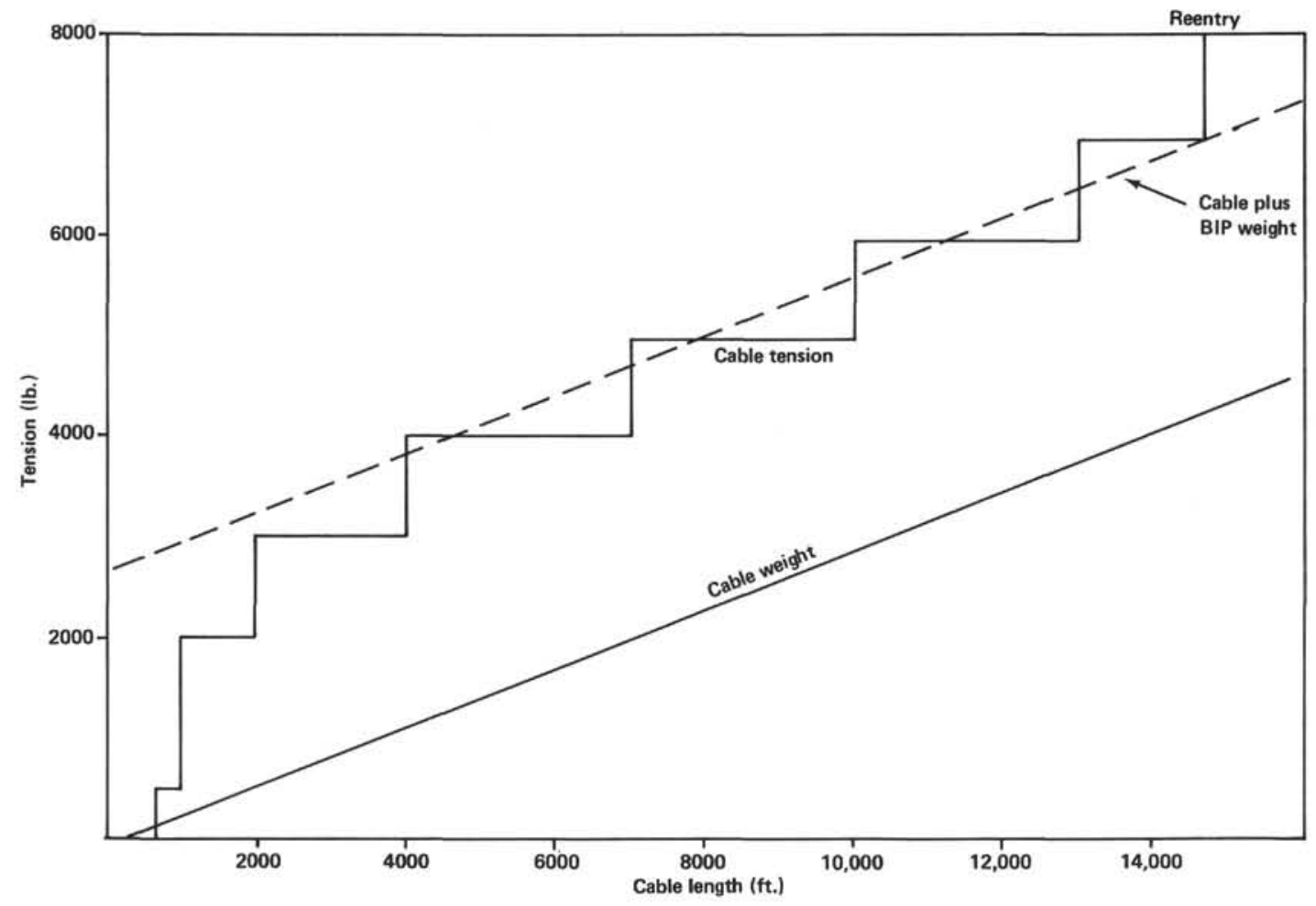

Figure 12. Diagram used to maintain cable tension at acceptable levels during deployment.

occurred when there was only a short cable-drill string out. As the cable-drill string length increased, the cable stiffness decreased, resulting in decreased dynamometer oscillations at the surface for approximately the same ship motions. At the reentry depth, the natural cable frequency approached $0.16 \mathrm{~Hz}$ (6-s period), which is similar to ship motion periods. At $4451 \mathrm{~m}$, cable dynamic tension amplitude (significant) appeared to be about $\pm 345 \mathrm{lb}$. with a free end. With the drill string constrained in the reentry cone, the significant amplitude did not increase above $350 \mathrm{lb}$. For the deployment phase, sea conditions remained approximately constant.

The nitrogen gas-pressurized passive heave compensator (HC) had a spring constant of 50 to $170 \mathrm{lb} . / \mathrm{ft}$. using the fixed accumulator. The gas $\mathrm{HC}$ cylinder retains a hardened spring action even when locked out. At the shallow to middle deployment depths, locking out the HC cylinder typically increased oscillatory amplitudes by a factor of 1.5 to 2.0 . At reentry depths, locking out the HC cylinder slightly decreased the oscillation, indicating that the $\mathrm{HC}$-cable system was near resonance. A preliminary calculation for the $\mathrm{HC}$-cable system indicates that it has a natural resonance frequency of about $0.12 \mathrm{~Hz}$ (8.3-s period).

While lowering the BIP within the borehole (4485$5094 \mathrm{~m}$ below sea level), the cable dynamic tension amplitude appeared to be about $\pm 900 \mathrm{lb}$. (significant) at an average frequency of $0.15 \mathrm{~Hz}$. With the BIP at the bottom of the borehole and the cable tensioned, the significant dynamic amplitude ranged form \pm 350 to $\pm 600 \mathrm{lb}$. and the average frequency ranged from 0.13 to
$0.19 \mathrm{~Hz}$. For the BIP at the bottom of the borehole and the cable slacked, the dynamic amplitude was $\pm 350 \mathrm{lb}$. at an average frequency of $0.16 \mathrm{~Hz}$. While retrieving the BIP, the dynamic amplitude was initially $800 \mathrm{lb}$, with an average frequency of $0.11 \mathrm{~Hz}$ when $4573 \mathrm{~m}(15,000 \mathrm{ft}$.) of cable was deployed. All data were taken with the HC system operating, except when momentarily locked out to record specific data. The cable tension during reentry is shown in Figure 13. An initial reduction in tension occurred as approximately $10 \mathrm{~m}$ of cable were paid out in preparation for the approximately $20-\mathrm{m}$ stab. The HCA-frame system fluctuated widely during the reentry stab.

\section{SUMMARY AND CONCLUSIONS}

From the preceding discussion, it is evident that the seismometer deployment conducted on Leg 78B was an engineering success. A 26 -ft.-long, 8-in.-diameter instrument weighing $2700 \mathrm{lb}$. was implanted in operating condition $609 \mathrm{~m}$ below the seafloor in an 11-in.-diameter borehole. Because the vertical and horizontal accelerations of the instrument never exceeded $6 \mathrm{~g}$ under normal handling conditions and the cable and drill string never became entangled, it is clear that the technique developed for the deployment of the Marine Seismic System is a practical, albeit expensive, way to deploy large instruments in boreholes in the seafloor.

\section{ACKNOWLEDGMENTS}

We would like to acknowledge the able assistance of Captain Clarke and his crew during the deployment of the MSS and the staff of the Deep Sea Drilling Project for their cooperation during all phases of the operation. 


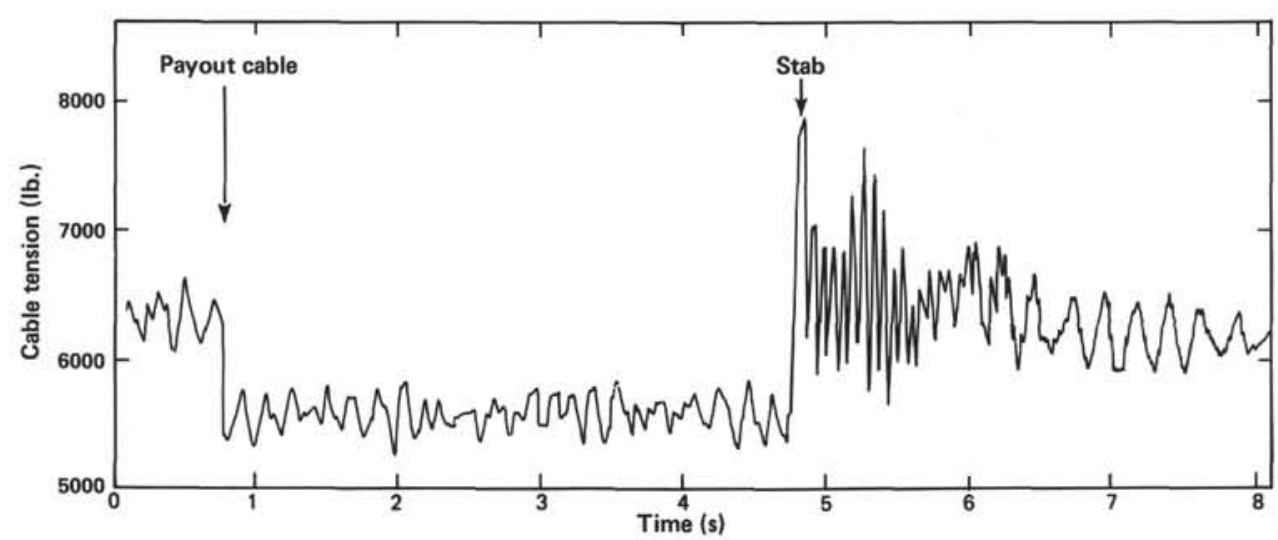

Figure 13. Dynamometer record prior to and during reentry. The winch operator anticipated the stab and paid out cable in order to have slack available for reentry.

\section{REFERENCES}

Stephen, R. A., Louden, K. E., and Matthews, D. H., 1980. The oblique seismic experiment on Deep Sea Drilling Project Leg 52. In Donnelly, T., Francheteau, J., Bryan, W., Robinson, P., Flower, M., and Salisbury, M., et al., Init. Repts. DSDP, 51, 52, 53, Pt. 1: Washington (U.S. Govt. Printing Office), 675-704.

Duennebier, F., Blackinton, G., and Gieskes, J., 1983. A man-made hot spring on the ocean floor. In Lewis, B. T. R., Robinson, P., et al., Init. Repts. DSDP, 65: Washington (U.S. Govt. Printing Office), 357-359.

Date of Initial Receipt: January 25, 1983

Date of Acceptance: July 18, 1983

\section{APPENDIX}

\section{Static and Dynamic Response of a Suspended Cable Due to} Current and Ship Motions ${ }^{1}$

In order to examine the probability of the drill pipe and the cable entangling, an extensive study was made by E. Gershunov to estimate the tension in the cable and the deflected shape of the cable due to currents and ship motion (Fig. 1), and to specify requirements for a tensioning system. It was felt that understanding and controlling these factors would aid in reducing the impact accelerations experienced during deployment and in reducing the probability of cable-drill pipe entanglement.

During the test in Hole 395A, the lower end of the cable was secured to the lower end of the drill pipe, and the upper portion of the cable was controlled by a ship-mounted constant tension winch. The weights, lengths, and tensions discussed here are applicable to the reentry of an existing borehole with seismometer package carried outside the drill string by an external cable. The cable is subjected to all of the motions induced in the pipe by ship roll, pitch, heave, and yaw plus additional stresses induced independently on the cross-sectional profile of the cable by currents in the water column.

The cable was assumed to be coaxial, hytrel-jacketed, spaced, armored, and torque balanced. It had a 17.6-mm O.D., a breaking strength of about $9500 \mathrm{~kg}$, and a longitudinal stiffness of $4.85 \times 10^{6} \mathrm{~kg}$. The dry and wet weights were 0.663 and $0.432 \mathrm{~kg} / \mathrm{m}$, respectively.

While it was not possible to describe all wave, sea, and current conditions likely to be imposed on the cable and pipe during deployment, average and limiting conditions served as useful guides. The surface conditions assumed for Site 395 included an average wave height of $1.1 \mathrm{~m}$ and an average wave period of $5 \mathrm{~s}$. Seas in excess of $1.5 \mathrm{~m}$ were assumed to occur less than $20 \%$ of the time. Typical surface currents were 17 to $35 \mathrm{~cm} / \mathrm{s}$, while midwater depth currents were not expected to exceed 10 to $15 \mathrm{~cm} / \mathrm{s}$. Strong bottom currents were considered extremely unlikely.

\footnotetext{
1 Summary of GMDI Report 006-002 by E. Gershunov for Global Marine Development, Inc., Newport Beach, CA 92663.
}

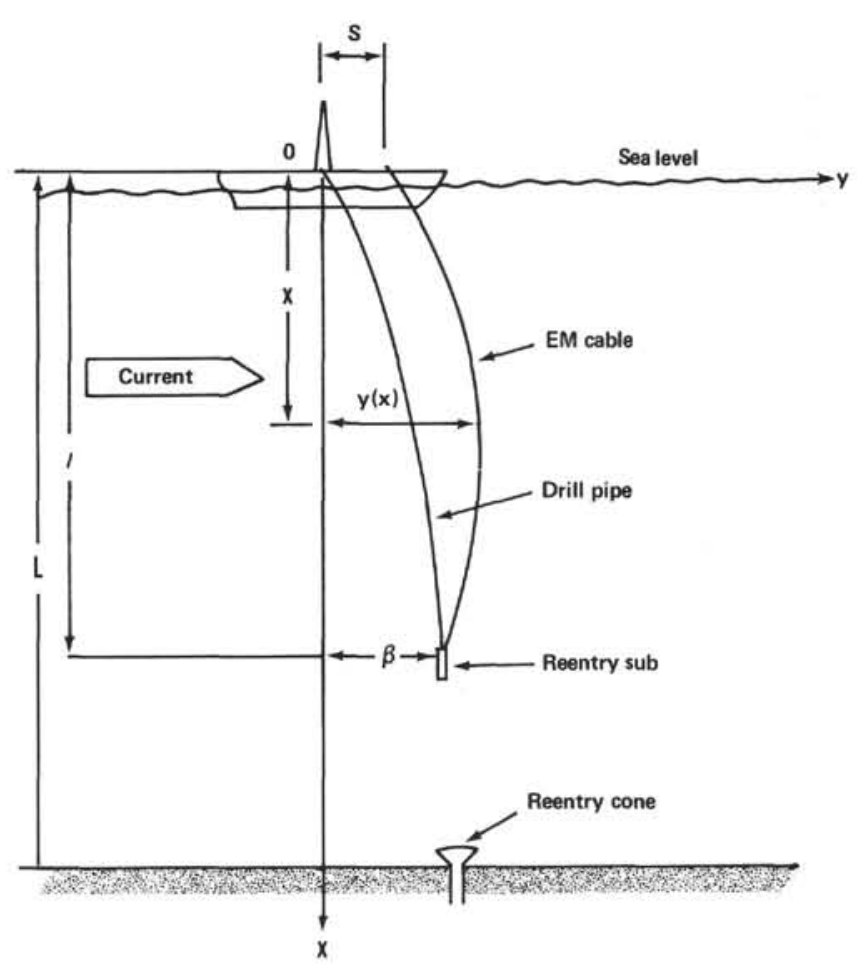

Figure 1. Drill pipe and cable configuration during reentry in the presence of a current. $\mathrm{L}=$ water depth, $1=$ drill pipe length, $\mathrm{x}=$ point at which deflection is measured, $s=$ initial offset between EM cable and drill pipe, $\mathrm{y}=$ deflection of cable, and $\beta=$ deflection of drill pipe.

\section{Results}

Although the calculations made during the course of the study are too tedious to reproduce here, many of the conclusions reached have considerable bearing on any future deployment of heavy equipment by cable. The conclusions are thus summarized below as an aid to future investigators.

1. Tension in the cable is controlled primarily by its own weight, by current, by the roll, pitch, and heave of the ship, and the release of the reentry sub. Surge, sway, and yaw-generated tensions are small and may be neglected. Cable weight and current generate static tension; ship motion and the release of the reentry sub cause dynamic tensions in the cable.

2. The maximum static tension is dependent on cable length and current and occurs at the upper end of the cable. For the case of a $100-\mathrm{cm} / \mathrm{s}$ current at the surface and a linear decrease in velocity to a 
value of $0 \mathrm{~cm} / \mathrm{s}$ at the bottom, the maximum tension is about $34 \mathrm{~kg}$. The main contributor to static tension is the weight of the cable. Additional tension due to current is in the range of 10 to $20 \%$ of the tension caused by the weight of the cable. The minimum static tension occurs at the lower end of the cable where the tension is limited to about 450 to $680 \mathrm{~kg}$ to avoid entanglement.

3. Generally, the dynamic tension applied to the upper end of the cable causes changes not only in the elongation of the cable but in its deflected shape. A conservative evaluation of the upper limit of the dynamic tension is based on two assumptions: the dynamic tension transforms completely into strain energy in the cable and only causes elongation; and the lower end of the cable is attached to the reentry sub-drill pipe and is immovable for any given cable length.

4. The dynamic tension depends on the wave frequency, cable length, and velocity of strain propagation in the cable $(3426 \mathrm{~m} / \mathrm{s})$. The maximum dynamic tension occurs at the lower end of the cable.

5. The first natural frequency of the cable in longitudinal oscillation ranges from 0.88 to 3.53 radians/s, which corresponds to a natural period of 1.8 to $7.1 \mathrm{~s}$, depending on the length of the cable. The frequency and period of the second mode range between 2 to 11 radi$\mathrm{an} / \mathrm{s}$ and $0.6-2.4 \mathrm{~s}$, respectively. The highest modes have periods of less than $2 \mathrm{~s}$, which correspond to the very low energy end of the sea energy spectrum (Table 1).

6. If the magnitude of the dynamic tension in the cable is considered to range from 225 to $680 \mathrm{~kg}$, then the magnitude of the dynamic tension applied to the upper end of the cable may be determined in accordance with Figure 2 for various wave frequencies and the first natural frequency of the cable. Figure 2 may be used to establish the tension transferred by the tensioning system to the cable.

7. The deflected shape of the cable was determined for a plane current profile (Fig. 3) and a spatial profile (Fig. 4). For comparison and evaluation of the possibility of cable-drill string entanglement, each figure contains the deflected shapes for both cable and drill pipe. These figures show that there is no reason to anticipate cable-drill pipe entanglement or cable wrapping for the conditions investigated if the current is sweeping the cable away from the pipe.

8. With the ship located $900 \mathrm{~m}$ downstream from the borehole, the slacked length of the cable is about $305 \mathrm{~m}$ and the tension at the borehole is estimated to range from 360 to $410 \mathrm{~kg}$ for a $50 \mathrm{~cm} / \mathrm{s}$ surface current, a linear current profile, a water depth of $4493 \mathrm{~m}$, and seastate 5 conditions.

9. If the cable is captured by the reentry sub after the BIP is released, two cases are possible: the cable is locked in the reentry sub; or the cable is pulled through the reentry sub. If the cable is locked at the reentry sub, tension, as registered by the shipboard dynamometer, will have a tendency to decrease as the pipe is withdrawn. If the cable is

Table 1. Circular frequency and period of the first $(\mathrm{N}=0)$ and second $(\mathrm{N}=1)$ longitudinal oscillation modes of the EM cable.

\begin{tabular}{cccccc}
\hline & $\begin{array}{c}\text { Cable } \\
\text { Length } \\
\text { (ft.) }\end{array}$ & 5000 & 10,000 & 15,000 & 20,000 \\
\hline $\mathrm{N}=0$ & $\begin{array}{c}\text { Frequency } \\
\text { (radians/s) } \\
\text { Period } \\
\text { (s) }\end{array}$ & 3.53 & 1.77 & 1.17 & 0.88 \\
$\mathrm{~N}=1$ & $\begin{array}{c}\text { Frequency } \\
\text { (radians/s) }\end{array}$ & 10.6 & 5.5 & 5.4 & 7.1 \\
& $\begin{array}{c}\text { Period } \\
\text { (s) }\end{array}$ & 0.6 & 1.6 & 1.8 & 2.4 \\
\hline
\end{tabular}

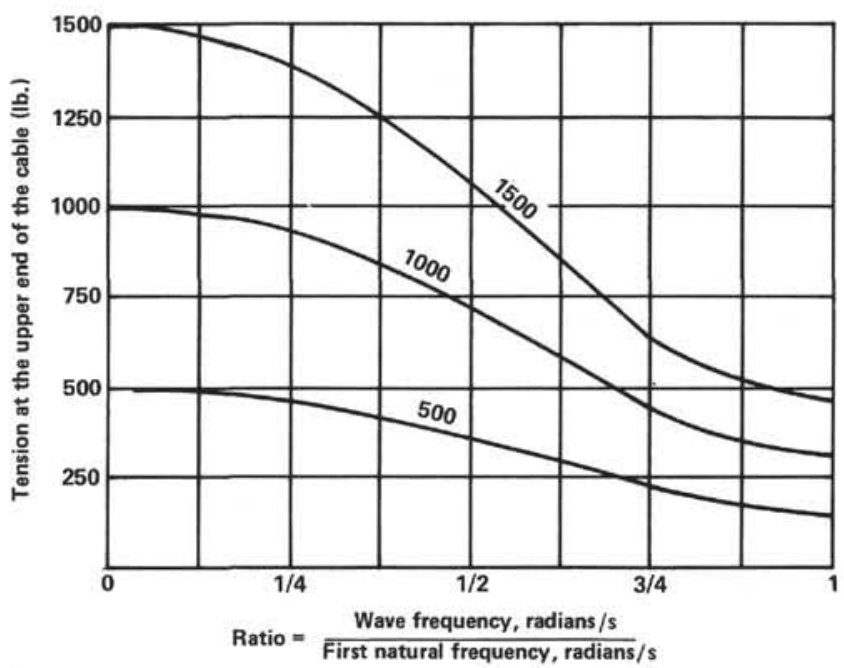

Figure 2. Dynamic tension at the upper end of the cable versus the ratio of the wave frequency to the first natural frequency of the cable for dynamic tensions of 500,1000 , and $1500 \mathrm{lb}$.

pulled through the reentry sub, the observer will note an increase in tension as the BIP load is taken up by the cable but should see no additional tension.

10. Possible interference between the drill pipe and the cable after the BIP has been released may occur only in cases with no ship offset. If the reentry sub is raised $20 \mathrm{~m}$ and the ship is moved $150 \mathrm{~m}$ up current at 12 to $15 \mathrm{~cm} / \mathrm{s}$ in the presence of a $50-\mathrm{cm} / \mathrm{s}$ current, the pipe and cable will offset by about $125 \mathrm{~m}$. Other offset and current conditions do not indicate a real tendency for interference between the drill pipe and the cable after the BIP release.

11. Bottom currents cause significant bottom separation between the cable and the drill pipe. The computed relative configuration of the drill pipe and cable show that the separation is even larger if shear currents are present than in the case of bottom currents alone.

12. If the ship maneuvers upstream at a speed of about 12 to $15 \mathrm{~cm} / \mathrm{s}$, the deflected shape of the drill pipe and the cable suggest enough separation to avoid entanglement.

13. If the length of the cable is equal to the water depth, ocean currents may cause additional substantial tension in the cable due to its elongation. This additional tension is uniformly distributed along the length of the cable.

14. To decrease the tension due to currents that may be considered undesirable when applied to the lower end of the cable, the total released cable length is recommended to be about 5 to $6 \%$ more than the depth of the water plus the borehole.

15. To avoid kink formation in the cable and snap loading, it is recommended that the maximum tension at the upper end be maintained at approximately $10 \%$ more than the weight of the released length of the cable. In this case, the maximum tension at the lower end of the cable is expected to be no more than $10 \%$ of the maximum tension applied to the upper end.

16. For sea state 5 conditions, a water depth of $6100 \mathrm{~m}$, a $6400-\mathrm{m}$ cable length, no ship offset, a linear current profile with a $100-\mathrm{cm} / \mathrm{s}$ current at the surface and a $0-\mathrm{cm} / \mathrm{s}$ current at the bottom, the maximum tension at the upper end of the cable will be about $7710 \mathrm{~kg}$, and the maximum tension at the lower end $710 \mathrm{~kg}$.

17. During Leg $78 \mathrm{~B}$, no snap loads appeared in the cable for any of the conditions tested and described. 


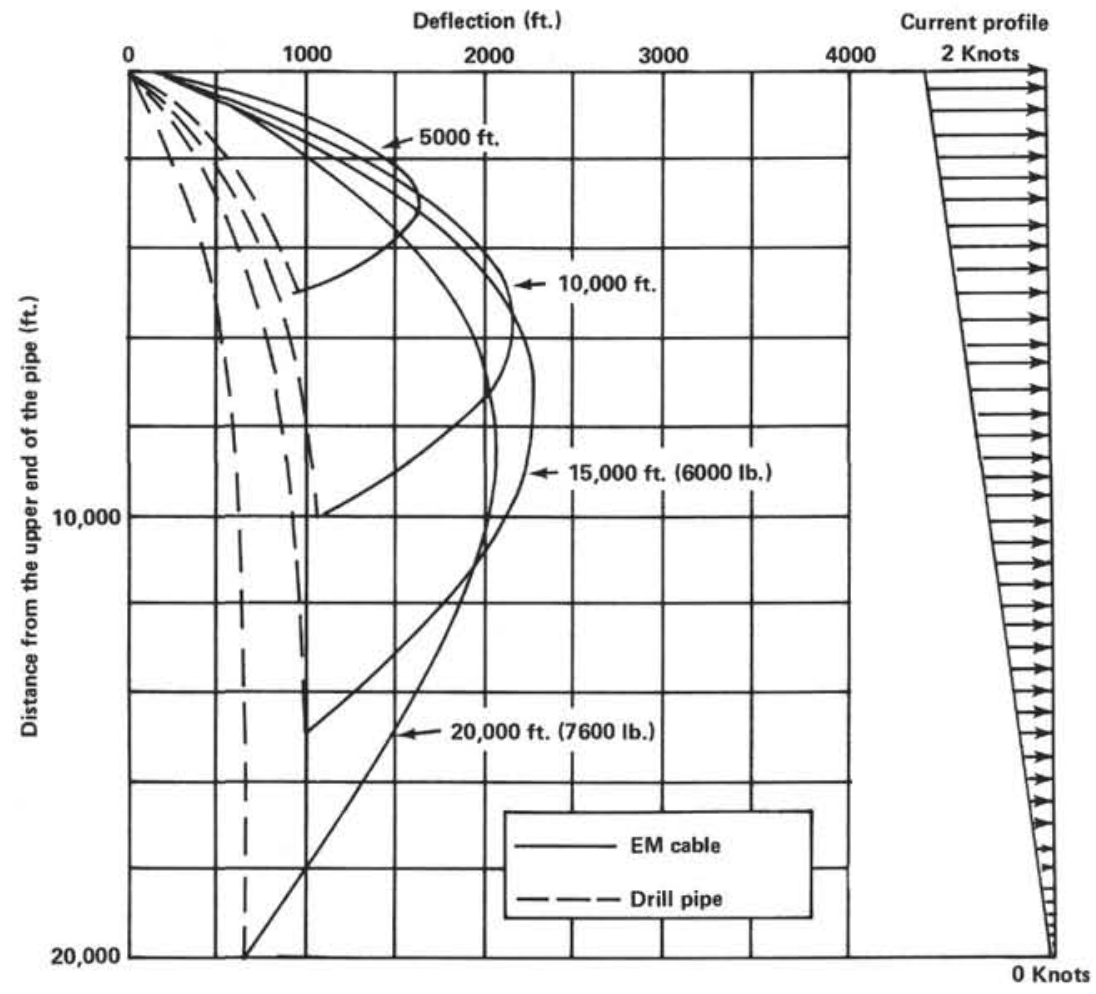

Figure 3. Deflections introduced in the cable and drill pipe by a 2-knot current, which decreases monotonically with depth.

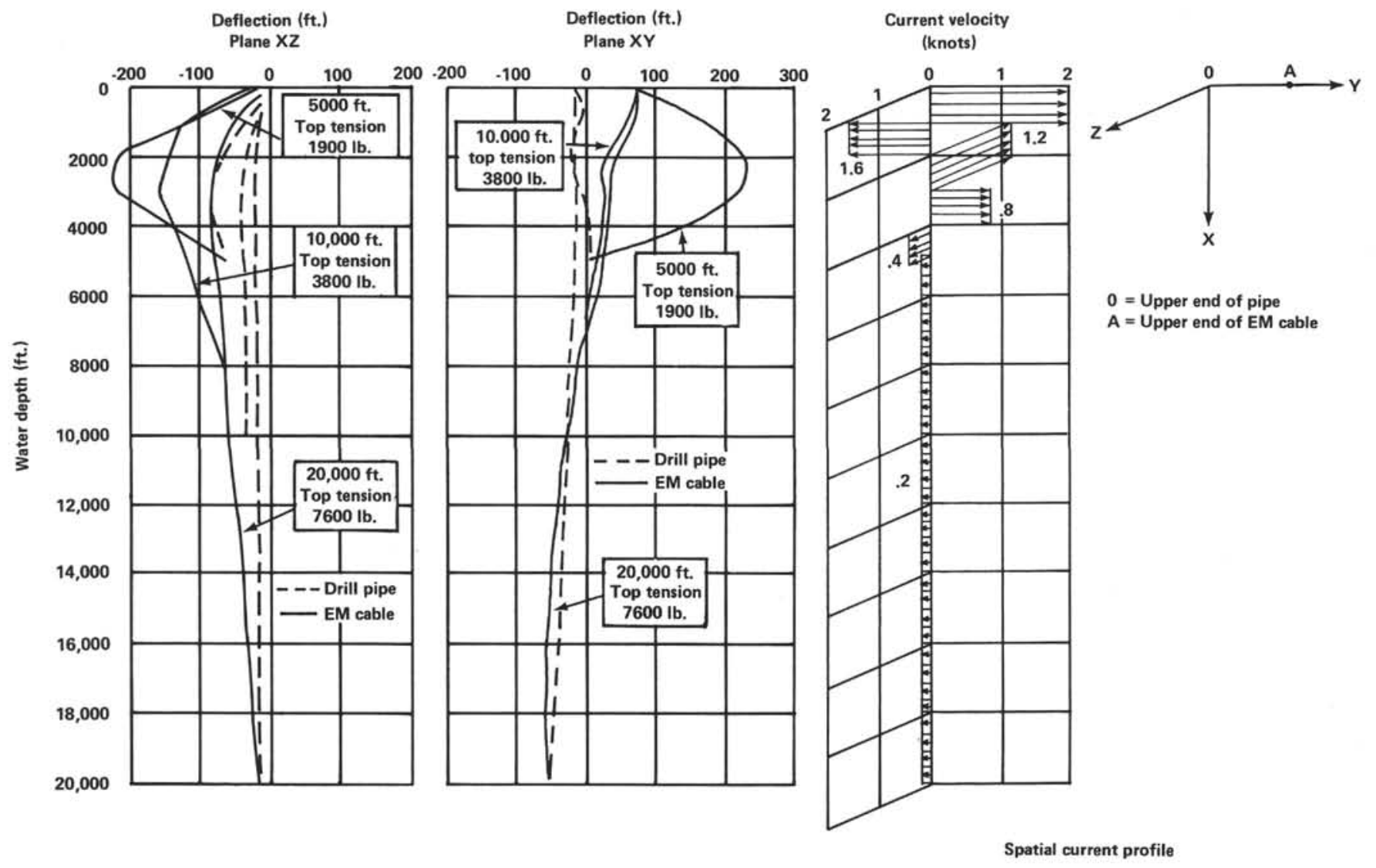

Figure 4. Deflected shape of cable and drill pipe due to a spatial current profile for 5000-, 10,000-, and 20,000-ft. water depths. 